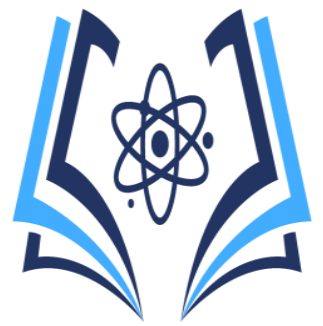

\title{
Fracturas en el ámbito prehospitalario
}

\author{
Fractures In The Prehospital Field \\ Fracturas en el ámbito prehospitalario
}

\author{
Raúl Ávila Ruíz ${ }^{1}$ \\ Jean Palma Ponce ${ }^{2}$ \\ José Loor Bravo $^{3}$ \\ Ronny Montesdeoca Alcívar ${ }^{4}$
}

${ }^{1}$ Instituto Tecnológico Superior Portoviejo, eduardo_avila@ hotmail.es, ORCID ID: 0000-0003-09616859

${ }^{2}$ Instituto Superior Universitario Portoviejo, jc_1992@hotmail.com, ORCID ID: 0000-0002-2612-7128

3Instituto Superior Universitario Portoviejo, Llloor2002@gmail.com

4Instituto Superior Universitario Portoviejo, ronnymontesdeoca274@gmail.com_ORCID ID: 0000-00024527-3411

Contacto: eduardo_avila@hotmail.es

Recibido: 25-09-2020

Aprobado: 15-12-2020

\section{Resumen}

Las fracturas son bastantes frecuentes, ocurren en cualquier parte, sus circunstancias hacen que se constituya en un problema de salud complejo, que de no tratarse adecuadamente con un tratamiento inmediato y perfecto desde el primer contacto con la víctima puede significar discapacidad e incluso la muerte.

Objetivo

Conocer el manejo que tiene el personal que presta servicios de atención pre hospitalaria en pacientes con fracturas.

Metodología

El diseño metodológico que se aplico es descriptivo y observacional se realizó la recolección de información por medio de encuestas online y entrevistas personales.

Resultados

Los procedimientos que realiza el personal encuestado al momento de la atención pre hospitalaria en su mayoría presentan complicaciones con su traslado pues no todos inmovilizan la fractura de manera adecuada al paciente pues desconocen de ciertas técnicas para diagnosticar la misma.

Palabras claves: Fracturas, Traslado, Inmovilización

Abstract

Fractures are quite frequent, they occur anywhere, their circumstances make it a complex health problem, which if not properly treated with immediate and perfect treatment from the first contact with the victim can mean disability and even death.

Aim

Know the management of the personnel who provide pre-hospital care services in patients with fractures.

\section{Methodology}

Information was collected through online surveys and personal interviews.

Results

Most of the procedures performed by the surveyed personnel at the time of pre-hospital care present complications with their transfer, since not all of them immobilize the fracture adequately for the patient, since they are unaware of certain techniques to diagnose it.

Keywords:

Fractures, Transfer, Immobilization

\section{Introducción}

En la actualidad se presentan tantos casos de accidentes traumáticos que ya compiten por igual o superan, las enfermedades más mortales, y las probabilidades de supervivencia de pacientes con trauma son cada vez más bajas. La mayoría de esos traumas se asocian a fracturas que frecuentemente conllevan a un riesgo de incapacidad de la funcionalidad normal del paciente y puede llevarlo hasta la muerte a corto plazo. El buen manejo inicial y la evolución del trauma pueden ser fundamentales para la recuperación, sin mayores complicaciones, $\mathrm{y}$ 
luego se rehabilita por completo el paciente afectado, llevándolo prontamente a su cotidianidad sin secuelas funcionales graves.

De una forma simple podemos definir que una fractura es la ruptura total o parcial de un hueso por diversas causas; lo más común es que se deba a un accidente, una caída fuerte o una lesión deportiva. Esta puede generar una deformidad dependiendo si hubo un desplazamiento de un extremo del hueso y ruptura de la continuidad de la piel (fractura cerrada o abierta).

La sintomatología más frecuente que acompaña a este tipo de lesiones es el dolor (que se hace muy intenso cuando se pretende mover la extremidad afectada), deformidad, desdibujo, acortamiento (dependerá mucho del tipo de rotura, de la cantidad y desplazamiento de los fragmentos), inflamación, aparición de hematoma y marcada impotencia funcional. Cualquier decisión de intervención ante una lesión de este tipo debe tener en cuenta la posibilidad de que se pueda producir una lesión en las partes blandas adyacentes (vasos sanguíneos, fibras nerviosas), hemorragia y shock hipovolémico, infección (en fracturas abiertas). El tratamiento definitivo de este tipo de lesiones pasa por el traslado del afectado a un centro sanitario y debe ser realizado por un facultativo.

En caso de que se tenga que socorrer a un accidentado en el que se sospeche este tipo de lesión se tienen que tener en cuenta algunas consideraciones:

- No movilizar al accidentado si no es estrictamente necesario.

- Retirar cualquier elemento compresivo (calzado, elementos de joyería).

- Explorar la movilidad, sensibilidad y pulso distales.

- Inmovilizar el foco de la fractura (sin intentar reducirla), incluyendo las articulaciones contiguas, con férulas rígidas y evitando los movimientos de la zona afectada o moviéndola si es preciso en bloque y bajo tracción.

- Si se trata de una fractura abierta, debe cubrirse la herida con apósitos estériles antes de proceder a la inmovilización. (1). El Objetivo de este proyecto es Conocer el manejo que tiene el personal que presta servicios de atención pre hospitalario en pacientes con fracturas. Se realizó la recolección de información por medio de encuestas online y entrevistas personales.

\section{Materiales Y Métodos}

El diseño metodológico que se aplico es descriptivo y observacional. Se realizó la recolección de información por medio de encuestas online y entrevistas personales con el objetivo de conocer si el personal pre hospitalario cuenta con los conocimientos sobre las técnicas y procedimientos que se debe realizar para poder asistir de manera garantizada al paciente, dentro de esto es saber cómo inmovilizar una fractura y así poder lograr una mejor condición de transporte e ingreso al hospital.

La presente encuesta esta aplicada para poder medir el conocimiento acerca de las fracturas y el procedimiento adecuado, es decir síntomas y diagnósticos en los diferentes casos. Se solicita responder este documento con total sinceridad dicha información será guardada en absoluta reserva y se realizan encuestas personales a profesionales de la salud.

Entrevista Personal

Datos de control

Nombres del encuestador: Eduardo Ávila Ruiz Nombres del facilitador: Dr. Ítalo Peña Vera Fecha: 22/02/2021

Hora: $22 \mathrm{~h} 00$

Lugar: Hospital Rodríguez Zambrano

\section{Qué complicaciones pueden surgir en el tratamiento de una fractura}

Las complicaciones más frecuentes que se han visto $\mathrm{y}$ he adquirido experiencia es que las personas que no saben manejar estos tipos de fracturas pueden agravarla ya sea desplazando la fractura que ya existe o provocando un agravamiento de la lesión es decir extender un poco más esa fractura.

\section{Cómo se diagnostica una fractura}

Tenemos dos maneras la clínica cuando no disponemos de una imagen de rayo $\mathrm{X}$ que es lo más común que vamos a ver a fuera porque nadie porta un equipo de RX a primera mano vamos a tener primero la limitada movilidad de la extremidad afectada vamos a tener también la presencia de edema, rubor, dolor y muchas veces podemos diagnosticar mediante el tacto se puede escuchar un poco decrepito al dolor y se siente muy claramene, pero la más confiable es la radiografía.

\section{Cómo sería la inmovilización correcta en una fractura}

Por lo general siempre depende mucho de la extremidad afectada por lo general vamos a encontrar fracturas en miembros superiores 0 inferiores $y$ en esto se recomienda que la manipulación de estas a nivel pre hospitalario es la colocación de una valva.

\section{Cómo se atiende una fractura de antebrazo}

Bueno la atención para una fractura de antebrazo siempre va hacer la colocación de una valva 
posterior, pero en este caso es de colocarla de la manera anatómica del brazo siempre en flexión.

\section{Por qué las fracturas en pelvis son} las más graves

En este caso es por la posición anotómica por el compromiso de grandes bazos que se encuentran en ese nivel más los órganos.

\section{Cómo trataríamos las fracturas de columna vertebral}

Lo principal es proteger la zona cervical colocando un collarín y colocar al paciente en una tabla rígida hasta la atención hospitalaria y tener las imágenes de control.

\section{Si tenemos fracturas expuestas como clasificaríamos su gravedad.}

La gravedad de la fractura siempre tenemos una clasificación llamada Gustillo Anderson que se conoce en el ámbito hospitalario que se embaza en tres tipos:

El tipo 1 es la fractura con hueso al exterior con una herida de 1 centímetro. El tipo 2 es con una herida entre 1 a 10 centímetros

El tipo 3 es la herida mayor a 10 centímetros

Datos de control

Nombres del encuestador: Eduardo Ávila Ruiz Fecha: 22/02/2021

Hora: $19 \mathrm{~h} 00$

Lugar: Manta

Nombres del facilitador: Miguel Emilio Escobar Ruperti

Lugar: Portoviejo (entrevista por zoom)

\section{1. ¿Qué complicaciones pueden surgir} en el tratamiento de una fractura?

Las fracturas es una discontinuidad en los huesos, a consecuencia de golpes, fuerzas o tracciones cuyas intensidades superen la elasticidad del hueso. En una persona sana, siempre son provocadas por algún tipo de traumatismo, pero existen otras fracturas, denominadas patológicas, que se presentan en personas con alguna enfermedad de base sin que se produzca un traumatismo fuerte. Es el caso de algunas enfermedades orgánicas y del debilitamiento óseo propio de la vejez.

\section{2. ¿Cómo se diagnostica una fractura?}

Se puede diagnosticar por la clínica mediante un examen físico de la estructura lesionada tomando en consideración una extremidad, la inferior al presentar impotencia funcional, edema, crepitantes a la digito presión leve y pulsos se pudieran correlacionar con una fractura, sin olvidar que el examen complementario de imagen (rayos $\mathrm{x}$ ) es el gold estándar para diagnosticar una fractura.

\section{3. ¿Cómo sería la inmovilización correcta en una fractura? .}

$>$ Colocar en posición anatómica o funcional

$>$ Uso de vendaje, uso de férula de acuerdo al sitio de la lesión.

4. ¿Cómo se atiende una fractura de antebrazo?

$>$ Inmovilización

$>$ Uso de vendaje o férula

5. ¿Por qué las fracturas en pelvis son las más graves?

Porque en la región pélvica tenemos el paso de las arterias iliacas que son ramas de la aorta abdominal, la lesión de este tipo de vasos ocasiona un sangrado profuso.

6. ¿Cómo trataríamos las fracturas de columna vertebral?

$>$ Alineación manual

> Inmovilización con collarín de filadelfia

$>$ Valoración de signos vitales

$>$ Valoración de clínica sintomatológica

$>$ RX para descartar o comprobar lesión

\section{Si tenemos fracturas expuestas} como clasificaríamos su gravedad.

De acuerdo a la clasificación de Gustilo y Anderson:

Tipo i: fractura abierta con una herida $<1 \mathrm{~cm}$ de largo y limpia.

Tipo ii: fractura abierta con una laceración> $1 \mathrm{~cm}$ de largo sin daño extenso de tejidos blandos, colgajos o avulsiones. 


\section{Resultados}

Grafico 1

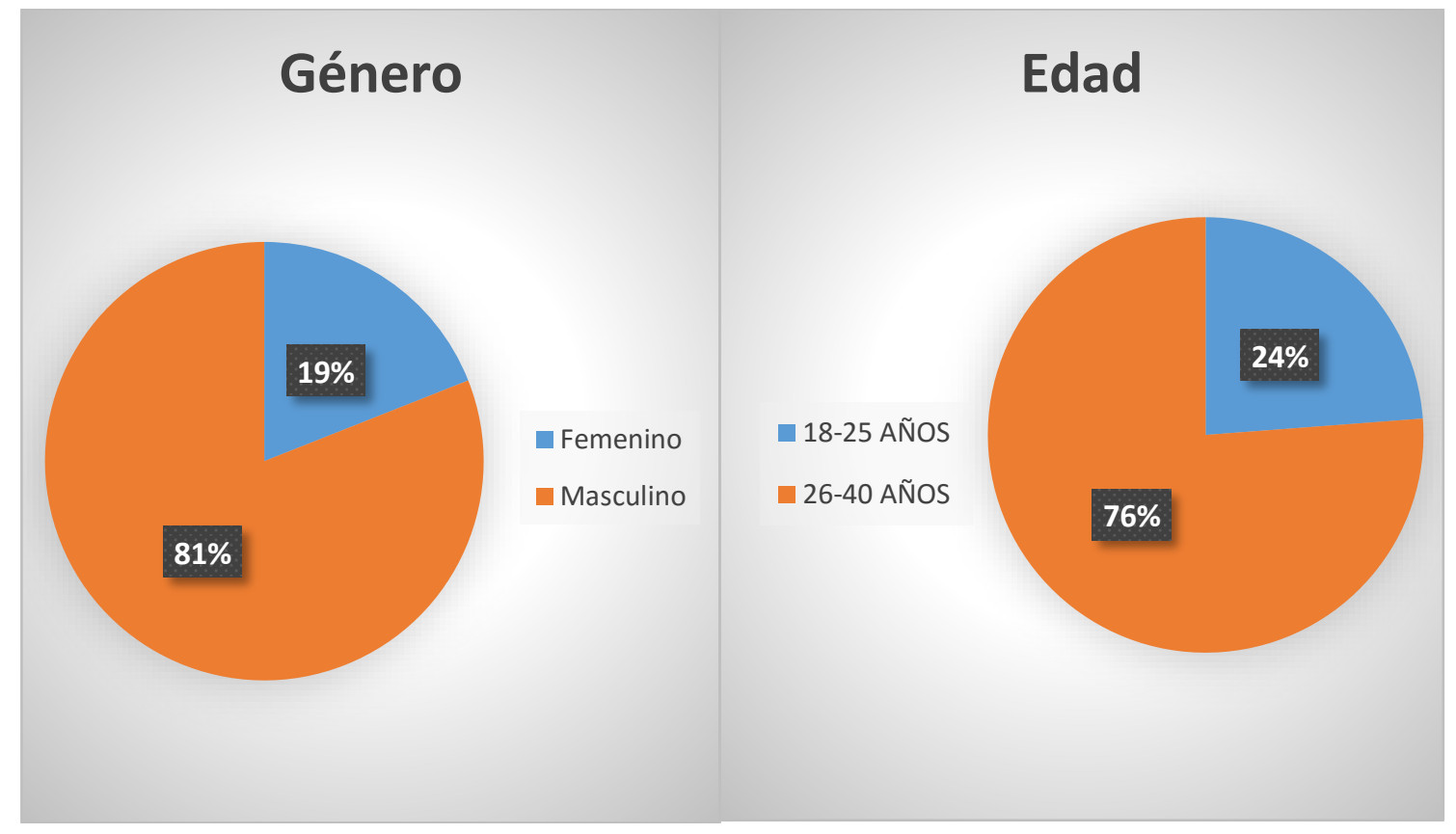

\section{GRÁFICA 2}

\section{Complicaciones al inmovilizar fractura}

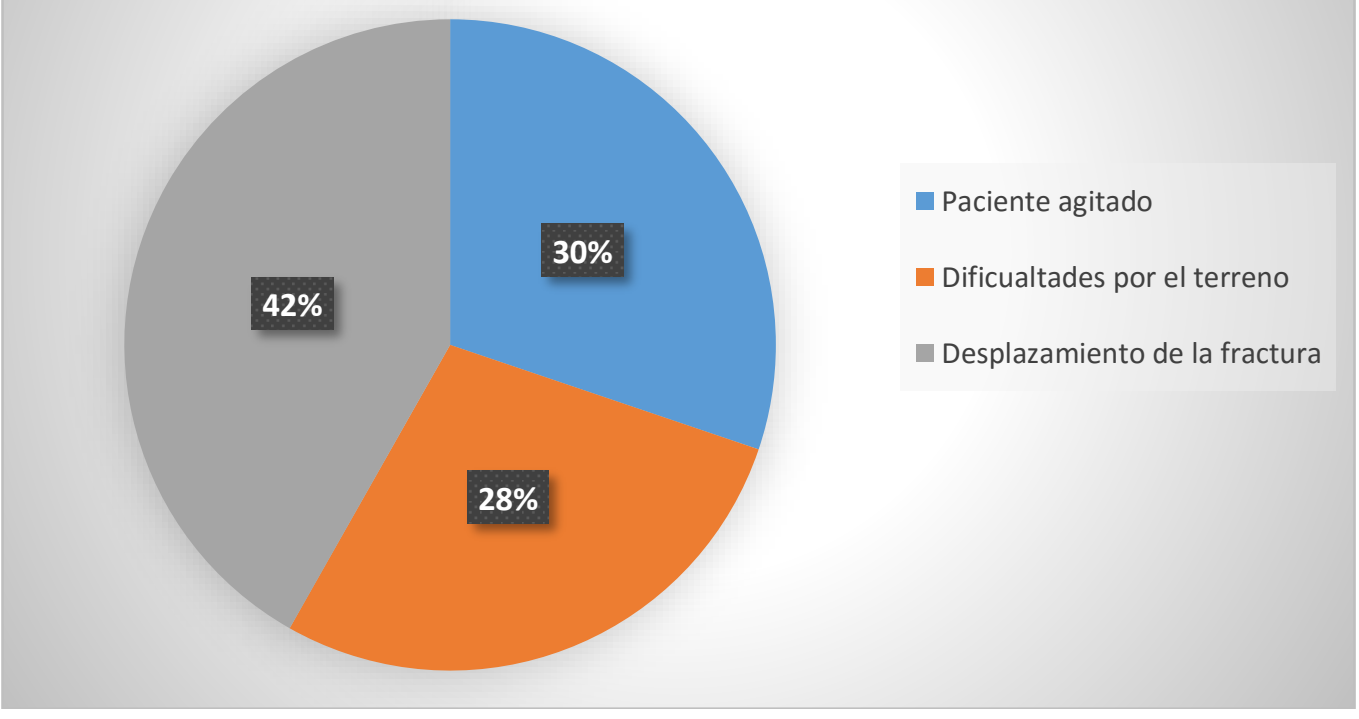

\section{Análisis}

Dentro de las complicaciones que existen para inmovilizar una fractura podemos observar que el desplazamiento de la fractura es el que mayor porcentaje obtuvo debido a que esta es una de las "El riesgo de complicaciones es elevado con fracturas abiertas (que predisponen a la infección) y con fracturas que interrumpen los vasos sanguíneos, la perfusión tisular, y/o mayores dificultades que se tiene al poder trasladar al paciente, esto debido a que en esta existe una separación de los extremos de la fractura lo implica un mayor riesgo para los tejidos que se encuentran alrededor de la lesión. nervios. Las fracturas cerradas que no involucran los vasos sanguíneos o los nervios, en particular aquellas que se reducen rápidamente,

https://revistas.itsup.edu.ec/index.php/higia 
tienen menos probabilidades de causar complicaciones graves". (2)

Contrastando con lo que dicen los doctores por la experiencia adquirida es que las personas que no saben manejar estos tipos de fracturas pueden agravarla ya sea desplazando la fractura que ya existe o provocando un agravamiento de la lesión es decir extender un poco más esa fractura.

\section{GRÁFICA 3}

\section{Conocimientos para diagnosticar una fractura}

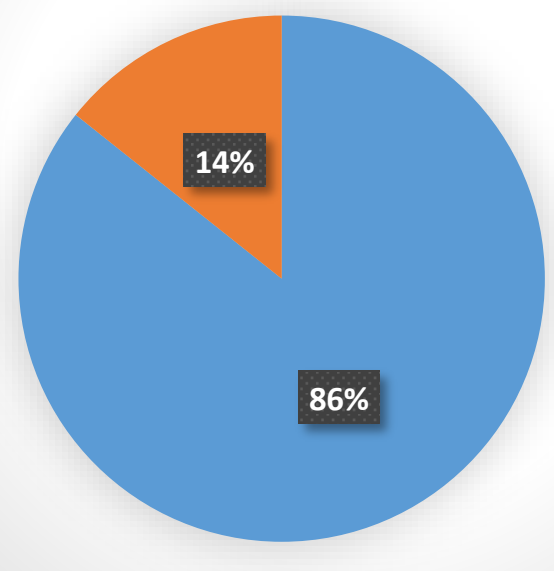

\section{Análisis}

Con un mayor porcentaje tenemos que los encuestados conocen sobre como diagnosticar, agregan que ellos revisan a los pacientes para verificar si existe una fractura con herida abierta $\mathrm{u}$ otra clase de fractura que requiera un estudio por imagen.

Lo agregado por uno de los doctores es que hay dos maneras de como diagnosticar una fractura: la primera que es la más común es la de rayos $\mathrm{X}$ y la otra diagnostico por la clínica mediante un examen fisco de la estructura lesionada considerando la extremidad lesionada.

Si el mecanismo de la lesión sugiere un daño potencial grave o múltiple (como en un accidente GRÁFICA 4 de vehículo de motor a velocidad alta o caídas de altura), los pacientes son evaluados primero de la cabeza a los pies en busca de lesiones graves en todos los aparatos y sistemas de órganos y de ser necesario son resucitados. Los pacientes, en especial aquellos con fracturas pelvianas o femorales, deben ser evaluados en busca de shock hemorrágico por una pérdida oculta de sangre. Si un miembro se lesiona, se evalúa de inmediato en busca de heridas abiertas y síntomas o signos de lesión neurovascular (entumecimiento, parálisis, mala perfusión) y síndrome compartimental

se requieren imágenes (generalmente radiografías) para confirmar el diagnóstico. (2)

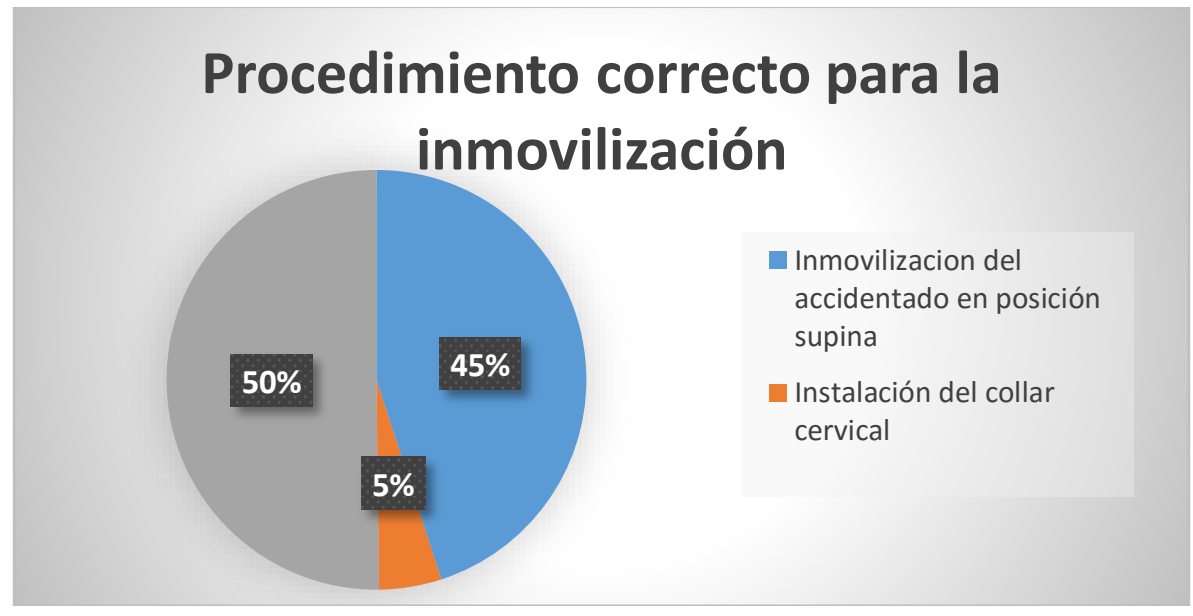

https://revistas.itsup.edu.ec/index.php/higia 


\section{Análisis}

El mayor del porcentaje nos habla que la inmovilización con valva de yeso es el procedimiento correcto que debe llevar el paramédico para la asistencia del paciente.

La colocación de una valva de yeso es una práctica muy habitual y consiste en la superposición de varias capas de yeso con el objetivo de conseguir la inmovilización de un miembro. Se utilizan para tratar lesiones menores, cuando existe un edema en una fractura o para servir de apoyo a un yeso cerrado. (3)

Nos confirma uno de los doctores que este es el más adecuado este siempre tiene que ser la colocación correcta de una valva posterior colocándola de manera anatómica del brazo siempre en flexión.

GRÁFICA 5

\section{Nivel de conocimiento sobre fractura de} antebrazo

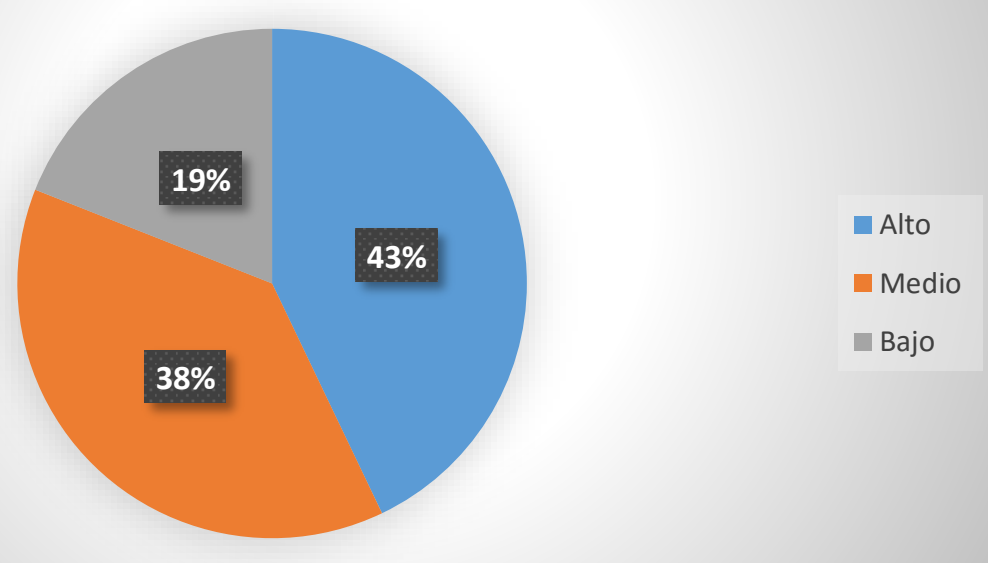

Análisis

En un mayor porcentaje nos habla que existe entre los encuestados un conocimiento medio sobre la fractura de antebrazo. Esto nos da a conocer que las fracturas de antebrazo pueden ocurrir cerca de la muñeca en el extremo más alejado (distal) del hueso, en el medio del GRÁFICA 6 antebrazo, o cerca del codo en el extremo superior (proximal) del hueso. En la mayoría de los casos, un antebrazo fracturado causa dolor severo.

El doctor Miguel nos habla de que la inmovilización se debe de hacer con el uso de vendaje o férula.

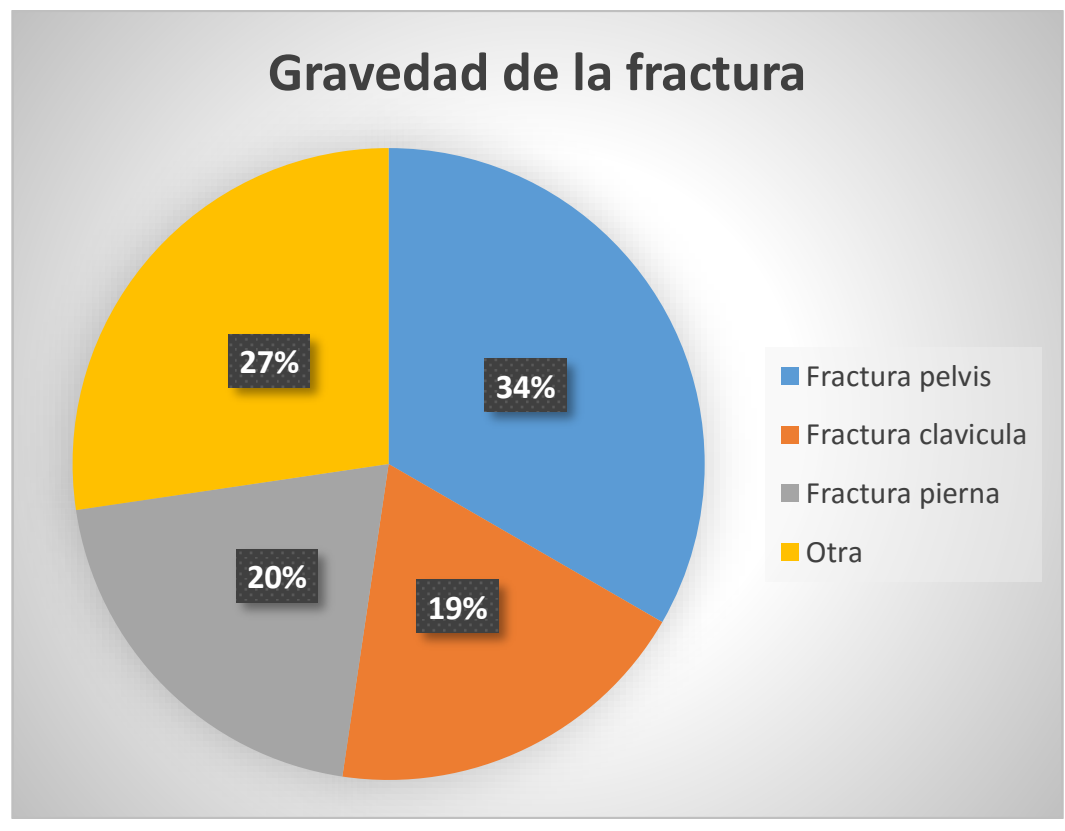




\section{Análisis}

La fractura de pelvis nos da un mayor porcentaje según los encuestados este tipo de son las de mayor gravedad. Las fracturas pélvicas pueden provocar hemorragias potencialmente mortales y pueden ir acompañadas de lesiones graves a otros órganos.

Los huesos de la pelvis forman la cavidad para la parte superior del fémur y, con el fémur, forman la articulación de la cadera. La pelvis está unida al cóccix (sacro) mediante ligamentos situados en la base de la columna vertebral. Muchos ligamentos sostienen estos huesos en su lugar. Los músculos del muslo (isquiotibiales y glúteos) están unidos a la pelvis por tendones. (2) En la región pélvica tenemos el paso de las arterias iliacas que son ramas de la aorta abdominal, la lesión de este tipo de vasos ocasiona un sangrado profuso, esto es lo que nos indica los doctores.

\section{GRÁFICA 7}

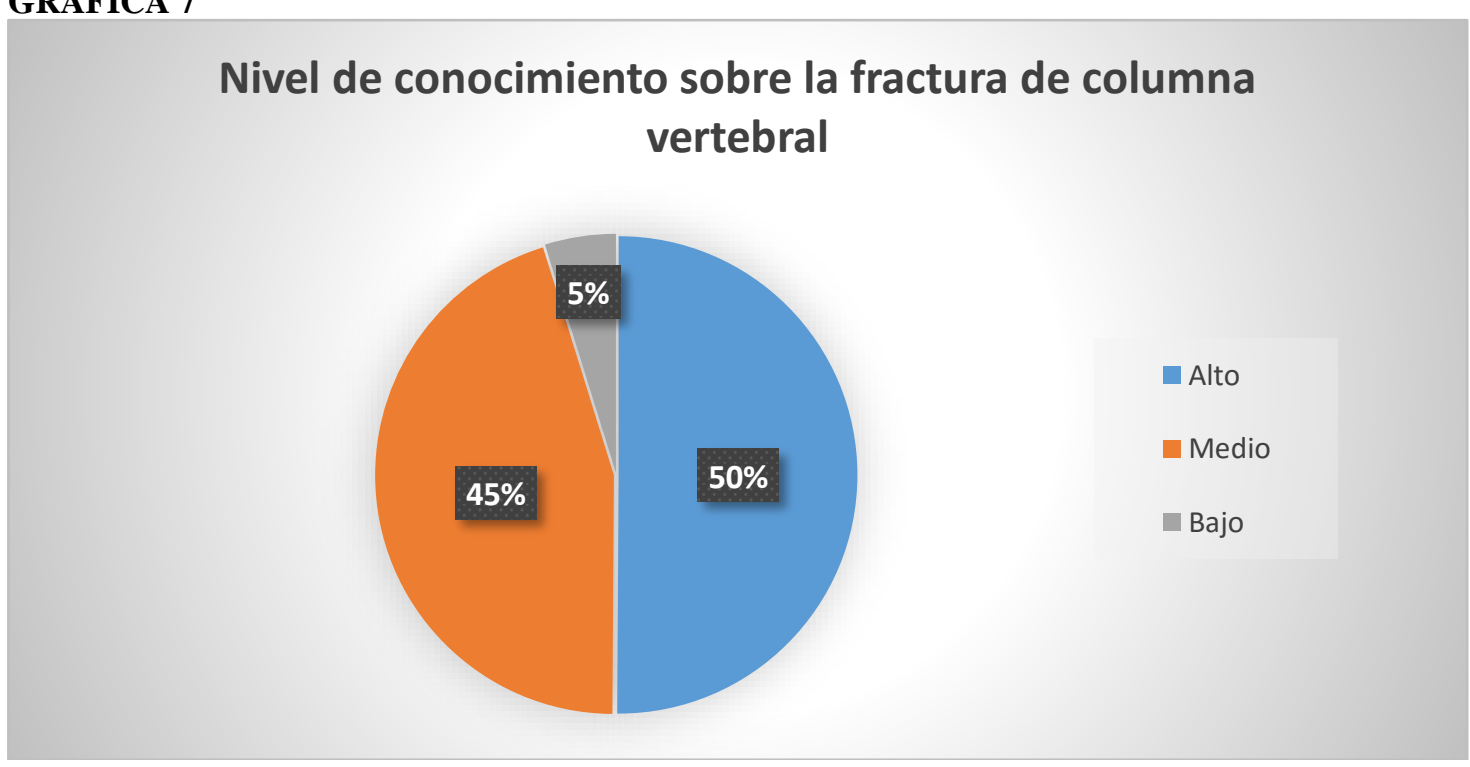

\section{Análisis}

La mayoría de los encuestados conocen sobre la fractura de la columna vertebral, una fractura en la columna (fractura por compresión vertebral) se da cuando uno de los huesos de la columna se rompe o colapsa. Esto de igual forma nos dan a entender los doctores debido a que es necesario proteger la zona cervical para lograrlo hay que colocar un collarín y llevar al paciente en una tabla rígida hasta la atención hospitalaria y de esta forma poder tener las imágenes de control que le sirvan al médico tratante.

Las lesiones de columna pueden implicar a una o más partes de la espalda y/o cuello: las vértebras, los discos intervertebrales, los músculos y ligamentos que las rodean, o la médula espinal y los nervios que se ramifican desde ella.

La complicación más seria asociada con la lesión de columna es la lesión medular. Puede provocar la pérdida de control y/o sensibilidad en la zona afectada. La médula o las raíces nerviosas pueden ser dañadas temporalmente al ser pellizcadas por los discos desplazados o por fragmentos de hueso roto. Si la médula se rompe parcial o totalmente, el daño puede ser permanente. (4) 


\section{GRÁFICA 8}

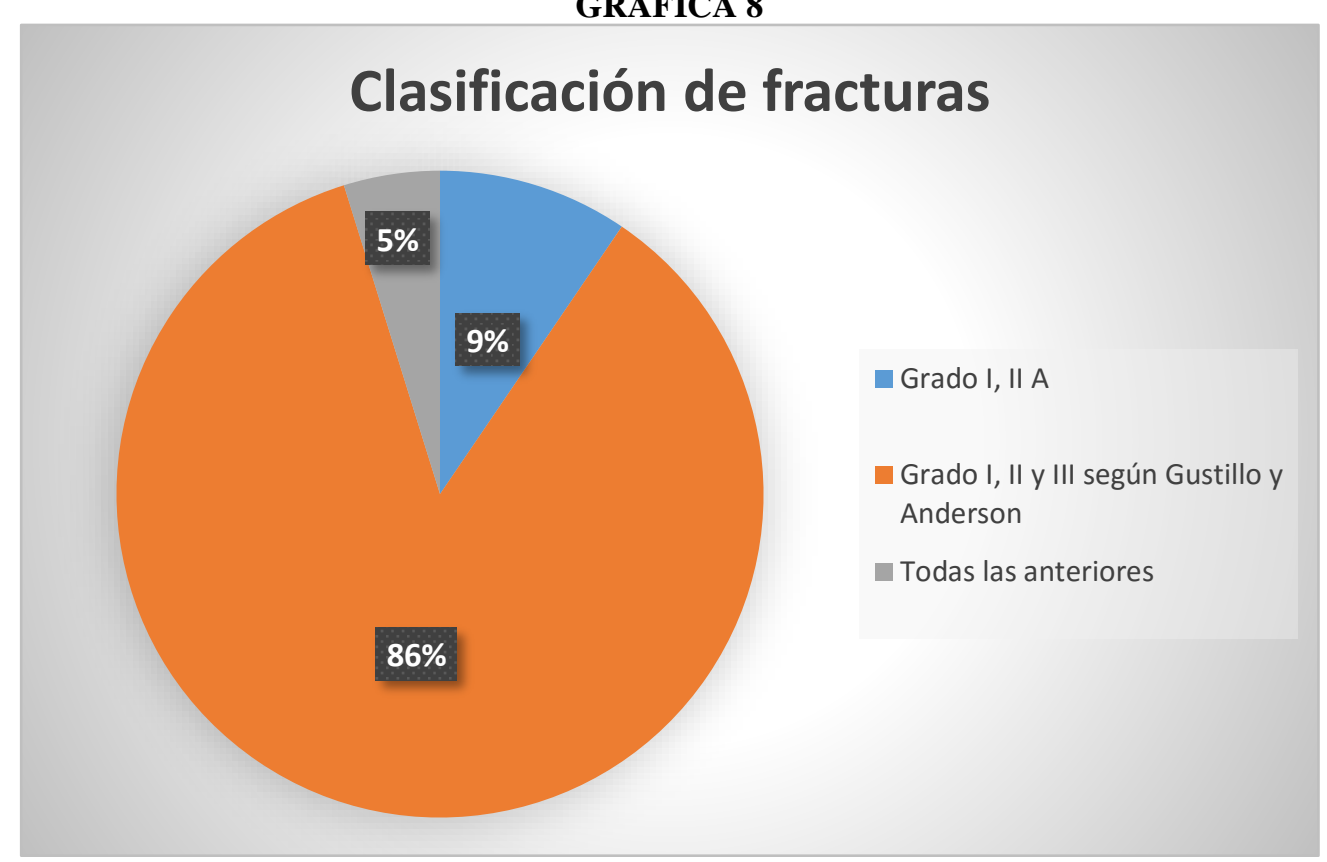

\section{Análisis}

Según la clasificación de Gustillo y Anderson las fracturas más frecuentes es la clase I, II, III, que representa el $86 \%$ seguido por grado I, II A y por todas las anteriores esto nos quiere dar a entender que las fracturas de grado I, II Y III son las de más gravedad.

Lo que nos indica los doctores que según la clasificación de Gustillo y Anderson que la gravedad de la fractura se conoce por el ámbito hospitalario que se basa en 3 tipos que son:

$>$ Tipo 1.- Fractura con hueso al exterior con herida de $1 \mathrm{~cm}$.

$>$ Tipo de 2.- herida entre $1 \mathrm{a} 10 \mathrm{~cm}$.

> Tipo 3.- herida mayor a $3 \mathrm{~cm}$.
La clasificación de Gustilo proporciona un sistema de definición manejable de la gravedad de las FA. Reconoce la diferencia entre los traumatismos de baja y de alta energía, la importancia de las lesiones de los tejidos blandos $y$, en especial, el efecto del despegamiento del periostio. Su valor pronóstico, en lo relativo al tiempo necesario para obtener la consolidación, se ha comprobado en varios estudios. De igual forma se ha considerado razonable la correlación entre el sistema de Gustilo y el valor pronóstico para la falta de unión de la fractura, la necesidad de injertos óseos y el funcionalismo de la extremidad. (5)

\section{GRÁFICA 9}

\section{Manejo inicial con un paciente con fracturas}

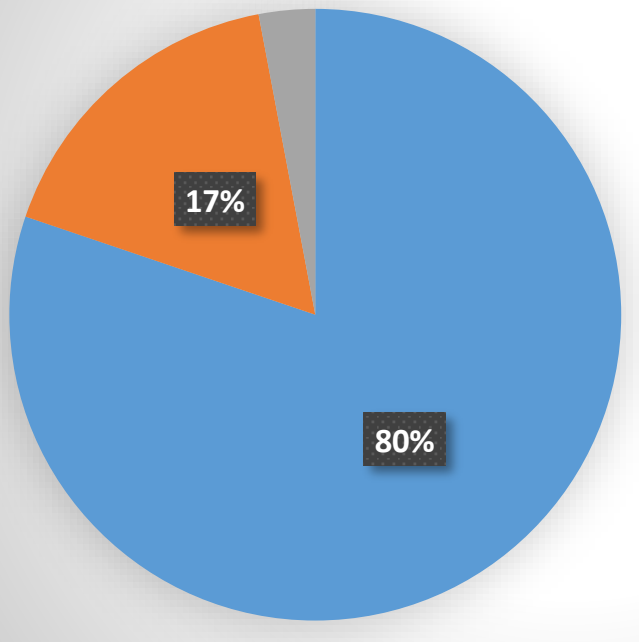

Descartar riesgo vital, descartar lesiones acompañantes, realizar inmovilización y trasladar a paciente.

Descartar lesiones, realizar inmovilización y trasladar a paciente.

Realizar inmovilización y trasladar a paciente. 


\section{Análisis}

Con un mayor porcentaje tenemos que en primer lugar hay que descartar un riesgo en el paciente después verificar si existen lesiones acompañantes para de esta forma realizar una inmovilización y poder realizar el traslado de forma segura.

El tratamiento inicial consiste en la estabilización del paciente, lo suficiente como para asegurar una adecuada vía área, respiración efectiva y circulación y poder identificar con detenimiento las lesiones implicadas.

\section{Discusión}

La información existente sobre las fracturas es extensa. En los últimos 50 años se ha propugnado que su clasificación sea la misma a nivel internacional, incluyendo los lineamientos de tratamiento específicos a cada hueso fracturado; se ha buscado la desaparición de epónimos. Actualmente, la clasificación aceptada a nivel mundial es la denominada AO.

Los factores que influyen directamente para que se presente una fractura son fuerzas externas que aplicadas directa o indirectamente sobrepasan el punto de ruptura del tejido óseo; los factores de riesgo son multifactoriales.

En la actualidad el incremento de la violencia, accidentes, han propiciado que la atención de pacientes crezca considerablemente, encontrando el problema dentro de las primeras causas de atención en los Servicios de Urgencias. Entre las principales causas de mortalidad en Ecuador, los accidentes constituyen la cuarta posición de mortalidad general, y son la primera

\section{Conclusión}

Como sabemos es de vital importancia que cualquier sistema de emergencias pre hospitalarias en el mundo está soportado por personal debidamente capacitado. En el tratamiento de fractura se debe establecer el tipo a la que está expuesto el paciente, cabe indicar que en ciertos casos estos pacientes no son atendidos en la manera indicada ya sea por falta de medios provocando en muchas ocasiones una irregular atención, las complicaciones en este tipo de fracturas están dadas ya sea por el desconocimiento del personal encargado, por la falta de los medios necesarios para la intervención, o por el manejo incorrecto dado por el tiempo hacen que dichas complicaciones eviten lograr un adecuado manejo en este tipo de emergencias provocando en muchas ocasiones que la vida del paciente se vea comprometida.
Una correcta evaluación es fundamental para el éxito de la atención pre hospitalaria. El objetivo de la evaluación primaria es determinar en 30 segundos el estado ventilatorio, hemodinámico y neurológico.

Simultáneamente se constatan o descartan puntos sangrantes, deformidades $o$ inestabilidad es decir los primeros 30 minutos son fundamentales para la toma de decisiones: pueden significar la diferencia entre la vida y la muerte y entre una calidad de vida aceptable o incapacitante. (6)

en población de 35 a 44 años, y niños por lo que tener los conocimientos y habilidades necesarias para brindar los cuidados con oportunidad y eficacia, representa una prioridad para el personal pre hospitalario.

La inmovilización debe ser realizada por personal capacitado para ello y en el mismo sitio del accidente. Los inmovilizadores no deben ser retirados por ningún motivo hasta que el paciente arribe al servicio de urgencias y sea valorado en forma individual por un paramédico entrenado en trauma. En el caso de las extremidades la inmovilización debe abarcar la articulación proximal y distal, dejando los dedos de la extremidad inmovilizada a la vista para poder vigilar la perfusión, elemento clave porque si no se detecta la isquemia precozmente, puede terminar perdiéndose la extremidad. Cuando sea posible, se deben vigilar los pulsos, pero si no, en su defecto, la perfusión en los dedos. De otro lado, si es posible la extremidad lesionada que es inmovilizada debe estar elevada para isminuir el edema por el traumatismo.

En el caso de deformidades evidentes de los miembros, y en presencia de una o varias fracturas (interrupción traumática de la integridad ósea) sin solución de continuidad en la piel (fractura cerrada), pero por ello muchas veces no menos grave, percibiremos una movilidad anormal del miembro, y una evidente crepitación e inmediatamente, si es en un miembro inferior lo colocamos, en una férula, presente en la dotación del vehículo de asistencia, siempre traccionando desde la parte distal (pierna si la fractura es de cadera o de fémur) o antepié (si es de tibia o de tobillo) con lo cual reducimos provisionalmente $\mathrm{e}$ inmovilizamos para su traslado.

En caso de fracturas abiertas (fractura con solución de continuidad en la piel, con o sin presencia de hueso en el exterior), en el miembro inferior debemos comprobar el pulso distal en la arteria pedia (se palpa en el dorso del pie junto al 
relieve del tendón extensor del primer dedo), taponar la herida con gasa estéril y solución antiséptica, y traccionando, proceder como en el caso anterior.

En el miembro superior, debemos antes de coger una vía para la reposición de fluidos, cerciorarnos mediante una breve exploración, que no existen indicios de fracturas en húmero, antebrazo o mano, así como de clavícula.

Ante la presencia de fracturas o luxaciones del miembro superior, intentaremos la correspondiente reducción, siempre traccionando distalmente a la lesión, como queda dicho e Bibliografía inmovilizaremos con el brazo pegado al cuerpo, en la clásica postura de Dessault, mediante un vendaje tipo Velpeau, presente también en el arsenal del vehículo de asistencias. En el caso de fracturas abiertas, debemos comprobar el pulso distal en la arteria radial (1/3 inferior del antebrazo sobre el propio radio) y proceder al vendaje e inmovilización.

Procediendo de esta manera, y una vez instauradas el resto de las medidas recuperadoras, tendremos al paciente listo para ser transportado sin graves riesgos a un centro hospitalario especializado.

1. Garrote A, Bonet R. Elsevier. [Online].; 2003. Available from: https://www.elsevier.es/esrevista-offarm-4-articulo-lesiones-traumaticas-extremidades-inferiores-13050007.

2. Campagne D. Manual MSD. [Online].; 2019. Available from: https://www.msdmanuals.com/es/professional/lesiones-yenvenenamientos/fracturas/generalidades-sobre-las-fracturas.

3. Martin D. Enfermería práctica. [Online].; 2014. Available from: https://enfermeriapractica.com/procedimientos/colocacion-de-ferula-de-yeso.

4. Chimbo R. Fractura de columna. [Online].; SN. Available from: https://www.manualdeprimerosauxilios.com/primeros-auxilios-en-fracturas/fractura-decolumna/.

5. Soler R. Fracturas abiertas. Elsevier. 2000;: p. 43-50.

6. Delgado T. Manejo del paciente traumatizado en Bélice. Revista de Información Científica. 2015 Julio 4; 92: p. 807-818.

7. Cuidate Plus. [Online].; 2021. Available from: https://cuidateplus.marca.com/ejerciciofisico/diccionario/fractura.html. 